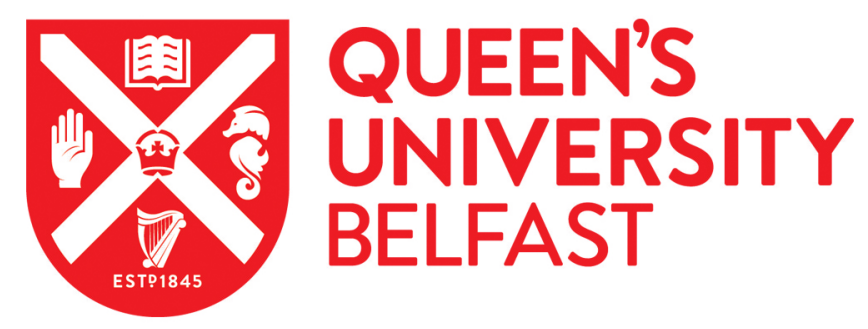

\title{
Power Loss and Thermal Analysis of a MW High Speed Permanent Magnet Synchronous Machine
}

Zhang, Y., McLoone, S., Cao, W., Qiu, F., \& Gerada, C. (2017). Power Loss and Thermal Analysis of a MW High Speed Permanent Magnet Synchronous Machine. IEEE Transactions on Energy Conversion, 32(4), 1468-1478. https://doi.org/10.1109/TEC.2017.2710159

\author{
Published in: \\ IEEE Transactions on Energy Conversion
}

\section{Document Version:}

Peer reviewed version

Queen's University Belfast - Research Portal:

Link to publication record in Queen's University Belfast Research Portal

\section{Publisher rights}

(C) 2016 IEEE.

This work is made available online in accordance with the publisher's policies. Please refer to any applicable terms of use of the publisher.

\section{General rights}

Copyright for the publications made accessible via the Queen's University Belfast Research Portal is retained by the author(s) and / or other copyright owners and it is a condition of accessing these publications that users recognise and abide by the legal requirements associated with these rights.

Take down policy

The Research Portal is Queen's institutional repository that provides access to Queen's research output. Every effort has been made to ensure that content in the Research Portal does not infringe any person's rights, or applicable UK laws. If you discover content in the Research Portal that you believe breaches copyright or violates any law, please contact openaccess@qub.ac.uk. 


\title{
Power Loss and Thermal Analysis of a MW High Speed Permanent Magnet Synchronous Machine
}

\author{
Yue Zhang, Student Member, IEEE, Seán McLoone, Senior Member, IEEE, Wenping Cao Senior \\ Member, IEEE, Fengyi Qiu, and Chris Gerada, Member, IEEE
}

\begin{abstract}
High speed permanent magnet synchronous machines (PMSMs) have attracted much attention due to their high power density, high efficiency, and compact size for directdrive applications. However, the consequent power loss density is high, and hence heat dissipation is a major technical challenge. This is particularly the case for high-speed operation. In this paper, a MW level high speed PMSM is designed and its electromagnetic and mechanical power losses comprehensively investigated using finite element analysis. The transient machine demagnetization performance is studied, and a composite rotor structure is proposed to improve machine anti-demagnetization capability. The temperature distribution of the proposed high speed PMSM is also analyzed using a fluid-thermal coupling method with calculated power loss. Experiments conducted on a prototype of the high speed PMSM demonstrate the effectiveness of the numerical models developed and validate the results obtained.
\end{abstract}

Index Terms--Demagnetization, finite element method, high speed PM machine, magnetic field, power loss, thermal analysis.

\section{INTRODUCTION}

$\mathrm{H}$ IGH speed permanent magnet synchronous machines (PMSMs) are increasingly popular owing to their excellent performance in industrial applications such as gas compressors, distributed power generation, electrical turbocharging, turbines and flywheel energy storage system [1]-[3]. Generally, these machines can be characterized by their high power density, compact size, high reliability and their suitability for direct-drive applications without gearboxes. Moreover, the PM machine is also attractive due to its remarkable efficiency at high operating speeds when

This work was supported in part by the Royal Society, UK and by the National Natural Science Foundation, China under Grant 5141101208.

Yue Zhang and Seán McLoone are with the School of Electronics, Electrical Engineering and Computer Science, Queens University Belfast, Belfast, BT9 5AH UK (e-mail: yzhang35@ qub.ac.uk; s.mcloone@qub.ac.uk).

Wenping Cao is with Power Electronics, Machines and Power System Group, Aston University, Birmingham, B4 7ET UK (e-mail: w.p.cao@aston.ac.uk).

Fengyi Qiu is with Jiangsu Aerospace Power Electric Co., Ltd, Jingjiang, China (e-mail: qiufengyi163@163.com).

Chris Gerada is with the Power Electronics, Machines and Control Group, University of Nottingham, Nottingham, NG7 2RD UK (e-mail: chris.gerada@nottingham .ac.uk). compared to induction and reluctance motor alternatives.

However, high speed rotation also results in some characteristic issues for PMSMs. High power density leads to high power loss density. Due to the high frequency of the magnetic field alternating in the steel core lamination, iron loss can be significantly high as it is closely related to the power frequency [4]. Particularly, rotor eddy current loss is of great importance as such loss heats the rotor directly [5]. Furthermore, rotor overheating may reduce machine performance and lead to the demagnetization of magnets. High speed PM machines have a smaller size than conventional machines and rotor cooling can only be performed through the air gap [6]. Therefore, thermal transfer poses a particular challenge for high speed machines.

Heat losses in high speed electrical machines reduce efficiency and increase operating temperature. Conventionally, PM machine iron loss can be predicted by the Bertotti iron loss model [7] with an improvement to account for the rotational flux [8]-[10]. The iron loss of an interior PMSM under a flux-weakening region is studied in [11] by employing variable iron loss coefficients. A systematic analytical method to predict eddy current losses in both surface-mounted PM and rotor container sleeve is illustrated in [12]. Eddy current loss due to armature reaction field is presented analytically in [13] with equivalent current sheet distributed over stator slot openings, but the slot effect is neglected. Finite Element Method (FEM) is widely adopted to study eddy current loss. Several methods to reduce rotor eddy current loss have been proposed, such as copper layer plating on the rotor alloy sleeve outer surface [14] or rotor sleeve grooving [15]. Demagnetization is discussed for PM machine in [16]. However, it is only partially studied based on the PM surface flux density without considering the whole PM demagnetization and its effect on machine performance. Electrical and thermal analysis for high speed machine is also extensively researched. The time saving lumped-parameter thermal network (LPTN) is utilized in [17], and computational fluid dynamics (CFD) method has been developed to improve prediction precision [2] [6] [18].

In this paper, a MW level high speed PMSM is designed and investigated with its electromagnetic and mechanical power losses analyzed. The iron loss is estimated with an 
improved method considering harmonics and rotational magnetic flux effects. The machine stator structure and rotor sleeve are investigated and studied using FEM to decrease rotor eddy current loss. The demagnetization behavior of the high speed PMSM with overload is also studied. A Composite rotor structure is proposed and investigated to improve machine anti-demagnetization capability in harsh conditions. Then the temperature distribution for the high speed machine is evaluated based on power loss and fluid-thermal coupling analysis. Finally, the high speed PMSM is prototyped and experimentally tested for validation purposes.

\section{HIGH SPEED PMSM DESIGN}

The design of high speed PMSMs is more complicated than a conventional machine, as their electromagnetic, thermal and mechanical aspects have all to be considered. To begin with, the initial machine structure and rotor dimensions must be determined and verified by mechanical analysis; then the machine power losses are estimated and processed by thermal analysis. The machine electromagnetic scheme should be adjusted until mechanical and temperature requirements are satisfied.

Surface-mounted and interior PM structures are two rotor options for PMSMs. The latter has a higher power density, while the former is considered to be a better choice for high speed applications as it can withstand greater stress resulting from high speed rotation. A good choice of PM material is also desirable for high speed PMSMs: SmCo can withstand temperatures up to $350{ }^{\circ} \mathrm{C}$, while $\mathrm{NdFeB}$ has the advantages of higher coercive force and larger remanence. Moreover, the mechanical performance of $\mathrm{NdFeB}$ is also superior to $\mathrm{SmCo}$ and this is important for high speed operation. Therefore, an NdFeB-based surface mounted PMSM is chosen in this research.

The number of poles in high speed machines is usually 2 or 4. Although the electrical frequency in 2-pole machines is lower, their end-winding length is longer than in 4-pole machines, which degrades machine dynamic performance at high speeds. As a result, a 4-pole structure is adopted.

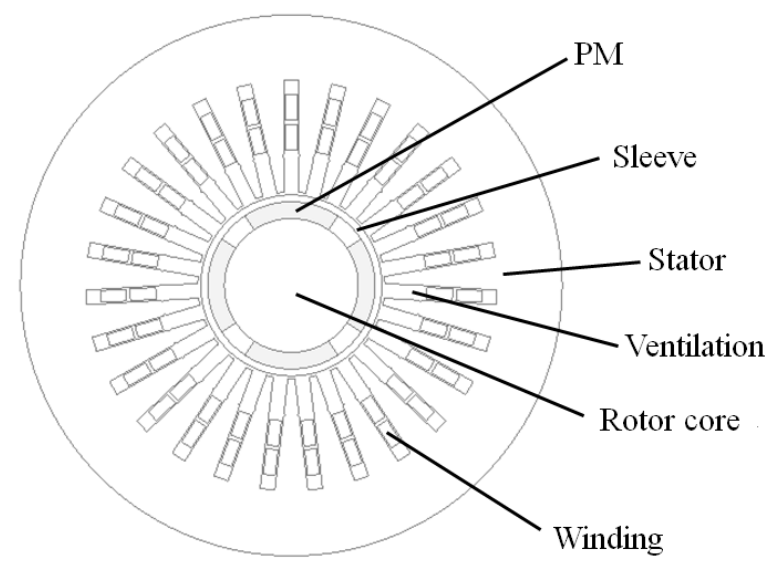

Fig. 1. High speed PMSM structure

In this paper, a $1 \mathrm{MW}$ PMSM is developed to operate at the rated speed of 18, $000 \mathrm{rpm}$. Its structure is shown in Fig. 1 and its key parameters are listed in Table I. A rotor sleeve is employed to protect PMs from the large centrifugal force due to high speed rotation. The sleeve, which is made from carbon fiber, is woven outside the PMs' outer surface, and wound around the rotor layer by layer. The iron core is laminated in the axial direction while the PMs are magnetized in radial direction. There are two pieces of magnets along the axial length of each pole to facilitate PM manufacture. The machine rotor is made of laminated iron to reduce rotor power loss.

TABLE I

HIGH SPEED PMSM PARAMETERS

\begin{tabular}{llll}
\hline \hline Item & Parameter & Item & Parameter \\
\hline Rated power & $1 \mathrm{MW}$ & Rated speed & $18000 \mathrm{rpm}$ \\
Current amplitude & $355 \mathrm{~A}$ & Rated frequency & $600 \mathrm{~Hz}$ \\
$\begin{array}{l}\text { Stator outer } \\
\text { diameter }\end{array}$ & $550 \mathrm{~mm}$ & Stator bore diameter & $190 \mathrm{~mm}$ \\
Rotor outer diameter & $184 \mathrm{~mm}$ & Air gap length & $3 \mathrm{~mm}$ \\
Iron core length & $400 \mathrm{~mm}$ & Slot number & 27 \\
Pole number & 4 & PM material & $\mathrm{NdFeB}$ \\
PM thickness & $17 \mathrm{~mm}$ & PM conductivity & $625000 \mathrm{~S} / \mathrm{m}$ \\
Winding layers & 2 & Conductors per slot & 6 \\
\hline \hline
\end{tabular}

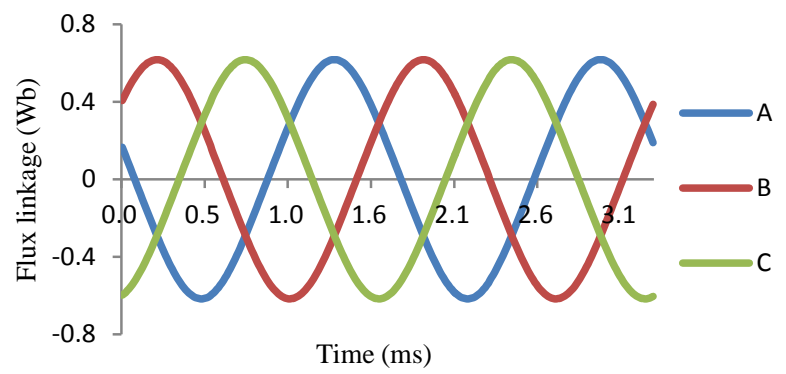

Fig. 2. Magnetic flux

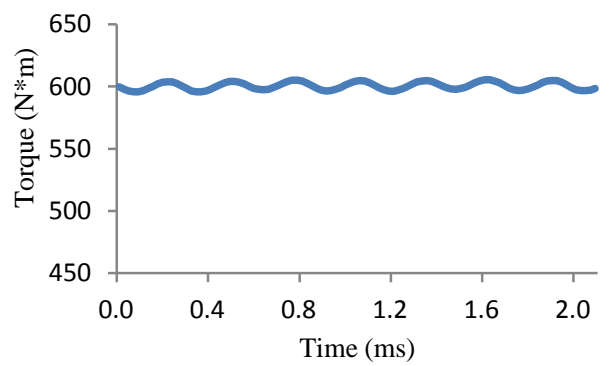

Fig. 3. Output torque at full load

Fig. 2 shows the magnetic flux linkage of the windings for the machine at rated speed with no load, while Fig. 3 presents the machine output torque at full load with rated speed, as determined by FEM analysis.

A deep slot structure is adopted in the high speed PMSM stator as the ventilation region for rotor cooling. The deep slot structure also gives rise to slot leakage inductance. For the high speed PMSM developed, the slot leakage inductance is $0.643 \mathrm{mH}$.

\section{POWER LOSS ANALYSIS}

\section{A. Iron Loss Analysis}

Iron loss accounts for considerable proportion of the total power loss as the frequencies in high speed machines are much higher than conventional ones. Generally, Iron loss in 
the steel core can be estimated by adding the hysteresis loss $P_{h}$, eddy current loss $P_{e}$ and anomalous loss $P_{a}$ in conventional method as [19]:

$$
P_{f e}=P_{h}+P_{e}+P_{a}=k_{h} \cdot f \cdot B_{m}^{2}+k_{e} \cdot f^{2} \cdot B_{m}^{2}+k_{a} \cdot f^{1.5} \cdot B_{m}^{1.5}
$$

where $k_{h}, k_{e}, k_{a}$ are the hysteresis, eddy current and anomalous loss coefficients, respectively. $f$ is the frequency and $B_{m}$ is the flux density magnitude. The anomalous loss coefficient $k_{a}$ is so small for the high grade steel utilized in the PM machine of this paper that this term can be neglected.

As the magnetic flux waveform in practical iron core is not exactly sinusoidal, the eddy current loss coefficient $k_{e}$ is also a variable of frequency $f$ [18]. Moreover, the additional iron loss due to rotational magnetic flux in the steel core is also necessary to be considered in iron loss analysis. The magnetic flux variation at each point of the iron core is obtained; the radial and tangential components of the flux density fundamental and harmonics are resolved by Fourier analysis; then the flux vector trajectory ellipse for each harmonic can be obtained and the short axis and long axis can be worked out. The additional core loss caused by the rotational field is proportional to the circular degree of the flux vector loci which is given by the short-axis-to-long-axis rate of the flux vector ellipse. Hence, the hysteresis and eddy current losses can be evaluated as:

$$
\begin{aligned}
& P_{h}=\sum_{i=1}^{M} k_{h}\left(B_{i}\right) f_{i}\left(1+\gamma D_{i}\right) \\
& P_{e}=\sum_{i=1}^{M} k_{e}\left(B_{i}, f_{i}\right) f_{i}^{2}\left(1+\gamma D_{i}\right)
\end{aligned}
$$

where $f_{i}$ is the $i$ order frequency, $B_{i}$ is the magnetic flux density at $f_{i}$ which is determined from Fourier analysis, $k_{h}\left(B_{i}\right)$ denotes the coefficient of magnetic flux density and $k_{e}\left(B_{j}, f_{j}\right)$ is the coefficient corresponding to frequency $f_{i}, D_{i}$ is the rate of short axis to long axis of the flux vector trajectory ellipse at harmonic order $i$ and $\gamma$ is a coefficient to consider the iron loss due to rotational flux [20]. In this study, $\gamma$ is taken as 0.96 based on iron core manufacture. Then the effects of high order harmonic components in the flux density and rotational flux can be taken into consideration for iron loss prediction.

Based on the improved iron loss estimation method, the iron loss for the machine at rated speed (18000 rpm) is 6116.8 $\mathrm{W}$. The iron loss due to fundamental magnetic field is the major component - accounting for $91.8 \%$ of the total iron loss. The losses due to the third, fifth and seventh harmonics represent $5.3 \%, 1.5 \%$ and $1.1 \%$, respectively, of the total iron loss. The iron loss caused by the high order flux density harmonic components account for about $8.8 \%$ of the iron loss due to fundamental component for the machine at rated speed. Therefore, the harmonic components contribute a considerable proportion of the iron loss in high speed PM machine.

Fig.4 presents a comparison of the iron losses calculated by the conventional method, the method considering iron loss due to harmonic components without rotational iron loss and the method considering both harmonics and rotational effects, plotted as a function of speed. It can be seen that for the machine operating at rated speed, the iron loss considering only harmonic components is $1380 \mathrm{~W}$ less than the iron loss considering both harmonic and rotational loss effects, which accounts for about $20 \%$ of the total iron loss. Hence, the PMSM core loss is affected not only by the alternating flux effect but also by the rotational flux effect, and it is valuable to take both into consideration for PMSM core loss estimation, especially for high speed applications.

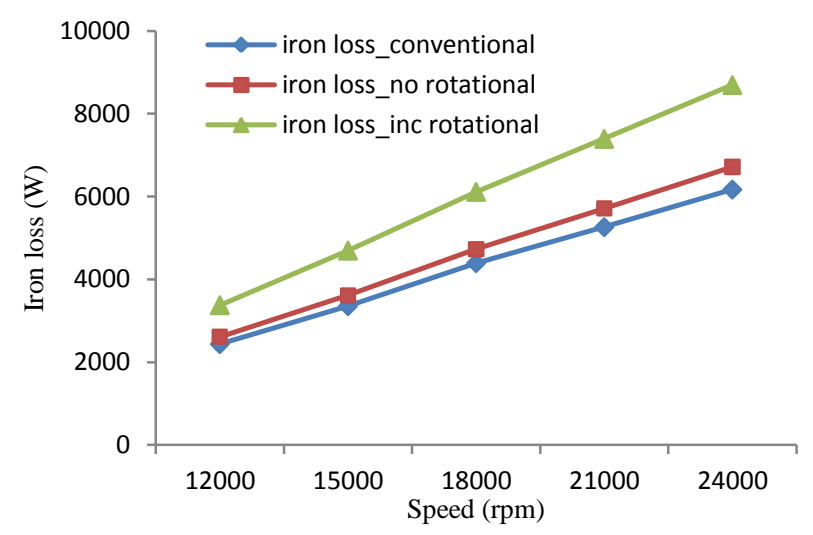

Fig. 4. Iron loss with machine speed

\section{B. Rotor Eddy Current Loss}

Rotor eddy current loss is critical in high speed PMSMs as it can only be removed through the air gap. The induced eddy current density $J$ in the rotor can be calculated from the waveform of the vector potential by performing a numerical time differentiation [21]:

$$
J=-\frac{1}{\rho} \frac{\partial A}{\partial t}+c(t)
$$

where $A$ is the magnetic vector potential, $\rho$ is the electrical resistivity and $c(t)$ is the function of time which guarantees a zero net current through the rotor. The rotor eddy current loss can then be obtained as:

$$
p_{e}=\int_{\text {rotor }} \frac{J^{2}}{\sigma} d V
$$

where $\sigma$ is the conductivity and $V$ is the rotor volume. In this paper, 2D time-stepping FEM (finite element method) is utilized with the field- circuit coupling method adopted. The stator end winding resistance and leakage inductance are considered by adding a corresponding resistance and inductance in the circuit. Therefore, the rotor eddy current loss can be calculated as:

$$
P_{e}=\frac{1}{k} \sum_{i=1}^{k} \sum_{e=1}^{m} J_{i e}^{2} \Delta_{e} \sigma^{-1} l
$$

where $J_{i e}$ is the eddy current density in the element $e$ at step $i$, $\Delta_{e}$ is the element area, $k$ is the step number and $m$ is the element number while $l$ is the rotor length [14].

As the PM has a low mechanical tensile capability, the rotor sleeve is always utilized to protect the surface-mounted PMs against the centrifugal force during high speed operation. However, the rotor sleeve itself can impact on the electromagnetic performance of the PMSM. In this paper, three materials, carbon fiber (conductivity: $2.20 \times 10^{4} \mathrm{~S} / \mathrm{m}$ ), Ti alloy (conductivity: $5.05 \times 10^{5} \mathrm{~S} / \mathrm{m}$ ) and copper $\left(5.98 \times 10^{7} \mathrm{~S} / \mathrm{m}\right)$, 
are considered for the rotor sleeve. The corresponding rotor eddy current density distributions of the machine at rated speed are shown in Fig.5.

It can be observed that the eddy current distribution is greatly influenced by the sleeve conductivity: the eddy current density is distributed all over the rotor, and the highest eddy current density area occurs at the PMs which is up to $2.60 \times 10^{6}$ $\mathrm{A} / \mathrm{m}^{2}$ with the carbon fiber sleeve. The eddy current is mostly distributed on the rotor sleeve, and the eddy current in the PMs is effectively reduced if the Ti- alloy sleeve is adopted. Since copper has much higher conductivity than PMs, the harmonics can hardly reach PMs, while the eddy current density is mainly distributed on the copper sleeve surface (up to $2.05 \times 10^{8} \mathrm{~A} / \mathrm{m}^{2}$ ). Such a high eddy current density would result in excessive rotor eddy current loss if utilizing a high conductivity rotor sleeve. However, it should be pointed out that a metal rotor sleeve with high conductivity normally also has much higher thermal conductivity than carbon fiber, which is helpful in rotor thermal dissipation. Although metal rotor sleeves have found application in high speed PM machines, this work considers carbon fiber as the rotor sleeve material.

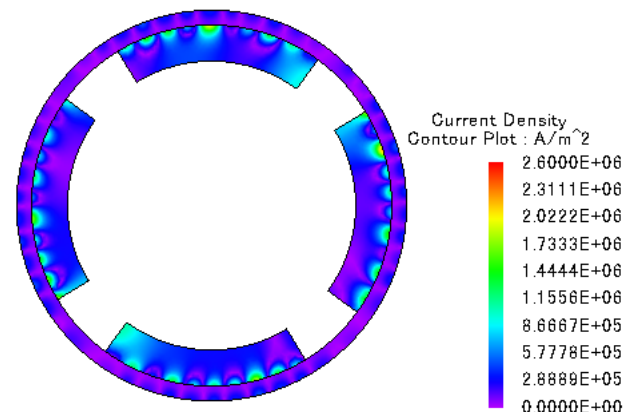

(a) Carbon fiber

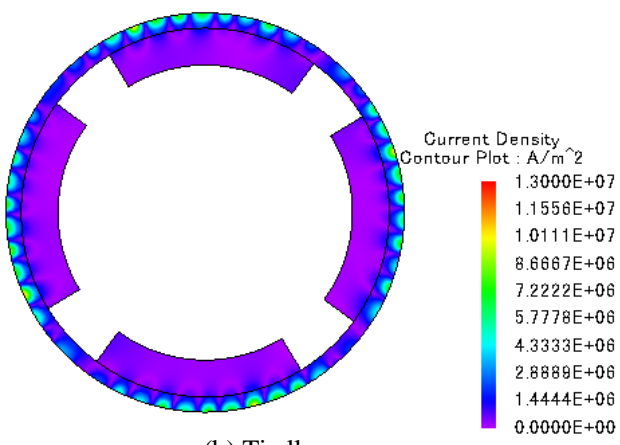

(b) Ti alloy

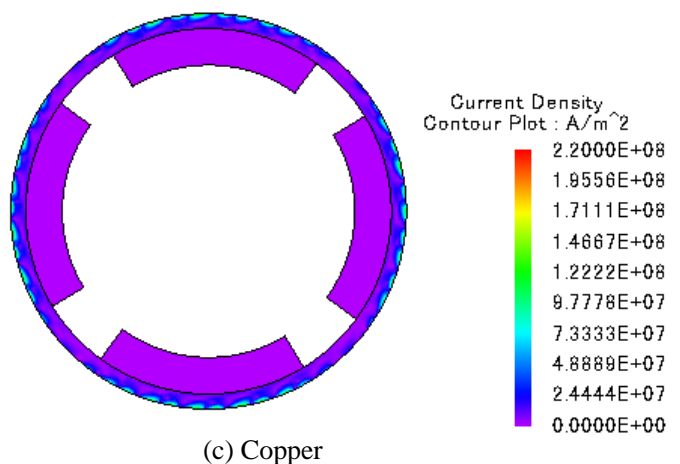

(c) Copper

Fig. 5. Eddy current density distribution for different sleeve materials
Table II compares the rotor eddy current losses calculated by FEM for the high speed PMSM with different stator slot numbers when operating at rated condition. All the machines have the same stator slot opening width, while windings and iron core lengths are slightly adjusted to maintain the same output torque of the machines. It can be seen that rotor eddy current loss is significantly reduced when the stator slot number rises. As the stator slot number has a critical impact on the machine magnetic field harmonics, a multi-slot stator structure is preferred for high speed PMSM design to reduce rotor eddy current loss effectively.

TABLE II

ROTOR EDDY CURRENT LOSS WITH STATOR SLOT NUMBER

\begin{tabular}{cccc}
\hline \hline Slot number & 18 & 24 & 27 \\
\hline Sleeve $(\mathrm{W})$ & 2567.1 & 2264.9 & 1571.3 \\
PM (W) & 3403.6 & 1192.1 & 1110.4 \\
Total $(\mathrm{W})$ & 5970.7 & 3457.0 & 2681.7 \\
\hline \hline
\end{tabular}

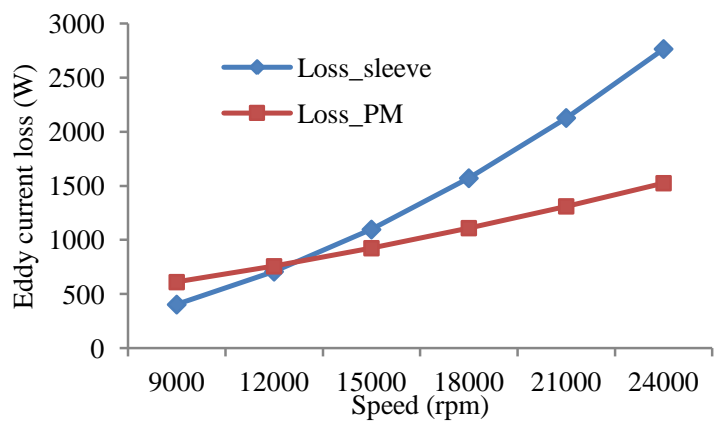

Fig. 6. Eddy current loss with machine speed

Fig. 6 shows the rotor eddy current losses in the carbon fiber sleeve and PMs for the high speed PMSM at different machine speeds. It is notable that the sleeve loss is nearly proportional to the speed squared, while the loss in PMs increases more slowly with rotor speed. In the low conductivity case of carbon fiber, the induced eddy current is not large enough to influence the magnetic field in sleeve. Hence, the eddy current is nearly proportional to the speed and thus the eddy current loss is almost proportional to the speed squared. Since PMs have a high conductivity, considerable eddy current can be induced on the PM's top side, and it can effectively prevent the magnetic field harmonics further penetrating into the PMs. Consequently, the eddy current loss in PMs increases at a relatively slow rate with machine speed increasing.

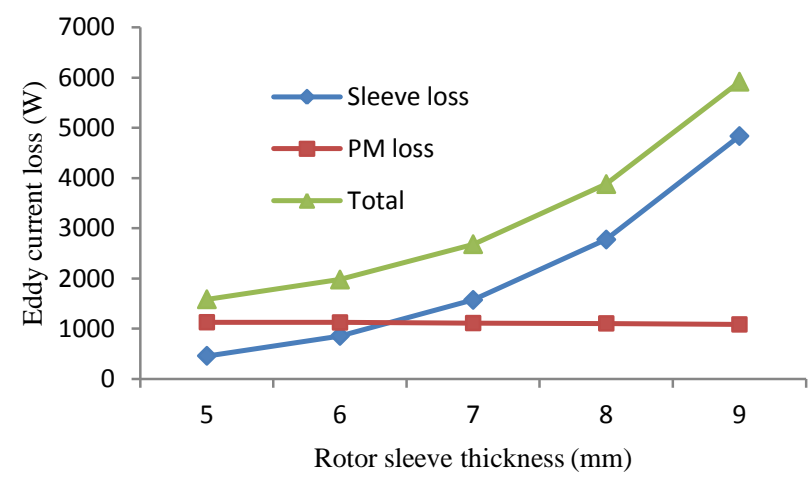

Fig. 7. Rotor eddy current loss with sleeve thickness 
Fig. 7 presents the rotor eddy current losses as a function of the carbon fiber sleeve thickness, while the distance between the stator inner diameter and the PM outer diameter is fixed at $10 \mathrm{~mm}$ and the high speed PMSM is operated at the rated speed $(18000 \mathrm{rpm})$ with rated load. As the rotor sleeve thickness increases, the total rotor eddy current loss increases dramatically since the harmonics effect is strengthened with reduced air gap. Therefore it is desirable to adopt a thin rotor sleeve to decrease rotor eddy current loss where mechanical requirements allow. The PM eddy current loss shows only a slight decrease with increasing sleeve thickness. This can be attributed to the low shielding effect from the carbon fiber sleeve, and the fact that the harmonics penetration depth in sleeve is much higher than the sleeve thickness. Hence, the magnetic harmonics are not effectively constrained by the sleeve and the PMs magnetic field does not change significantly. Therefore, the sleeve thickness has quite limited effect on PM eddy current loss variation. Table III further compares the eddy current losses with sleeve conductivity (sleeve thickness $7 \mathrm{~mm}$ ) for the machine with rated speed at rated load. It can be observed that the total rotor eddy current loss increases with the sleeve conductivity. Therefore, it is beneficial to utilize a low electrical conductivity sleeve to decrease the eddy current loss.

TABLE III

EDDY CURRENT LOSS WITH SLEEVE CONDUCTIVITY

\begin{tabular}{cccccc}
\hline \hline Conductivity $\left(* 10^{4} \mathrm{~S} / \mathrm{m}\right)$ & 1 & 2 & 3 & 4 & 5 \\
\hline Sleeve $(\mathrm{W})$ & 732.3 & 1456.9 & 2177.0 & 2891.6 & 3600.5 \\
PM $(\mathrm{W})$ & 1137.4 & 1122.0 & 1106.9 & 1092.2 & 1077.8 \\
Total $(\mathrm{W})$ & 1869.7 & 2578.9 & 3283.9 & 3983.8 & 4678.3 \\
\hline \hline
\end{tabular}

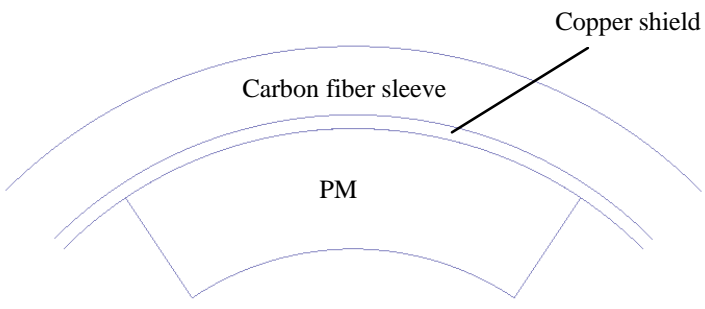

(a) Composite rotor structure

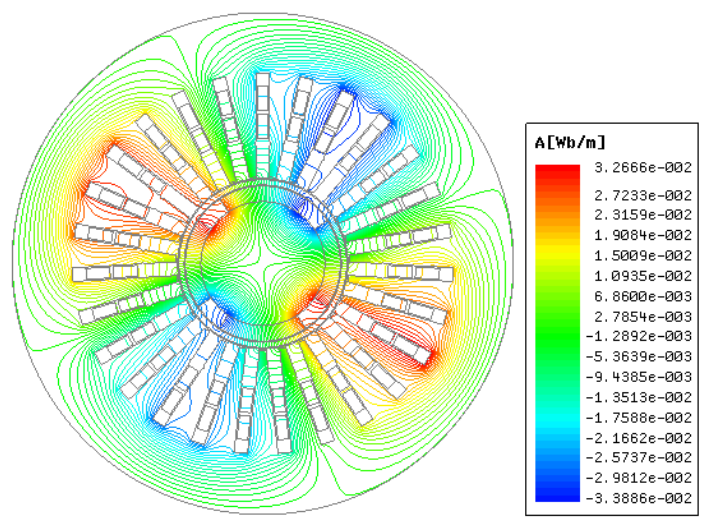

(b) Flux line distribution

Fig. 8. Composite rotor

As analyzed previously, the use of a copper sleeve with high conductivity can offer a dramatic shielding effect to PMs and stop harmonics penetrating into PMs. Then a composite rotor sleeve structure is studied to decrease the eddy current loss in PMs. As shown in Fig.8 (a), a copper shield is added between the carbon fiber sleeve and PMs. Figure 8(b) presents the flux line distribution in the machine with this configuration at rated condition, when the copper shield thickness is $1.2 \mathrm{~mm}$. The relationship between rotor eddy current loss and copper shield thickness is tabulated in Table IV for the machine with a fixed 3-mm air gap length at rated operation:

TABLE IV

EDDY CURRENT LOSS UNDER DIFFERENT COPPER SHIELD THICKNESS

\begin{tabular}{ccccc}
\hline \hline $\begin{array}{c}\text { Copper shield } \\
\text { thickness }(\mathrm{mm})\end{array}$ & $\begin{array}{c}\text { PM } \\
(\mathrm{W})\end{array}$ & $\begin{array}{c}\text { Shield } \\
(\mathrm{W})\end{array}$ & $\begin{array}{c}\text { Sleeve loss } \\
(\mathrm{W})\end{array}$ & $\begin{array}{c}\text { Total } \\
(\mathrm{W})\end{array}$ \\
\hline 0 & 1110.4 & - & 1571.3 & 2681.7 \\
0.3 & 142.8 & 2612.8 & 1377.9 & 4133.5 \\
0.6 & 47.1 & 2180.2 & 1320.7 & 3548.0 \\
0.9 & 25.5 & 1981.4 & 1280.8 & 3287.7 \\
1.2 & 19.0 & 1966.1 & 1242.9 & 3228.0 \\
1.5 & 23.4 & 2113.6 & 1203.3 & 3340.3 \\
1.8 & 32.3 & 2410.5 & 1159.5 & 3602.3 \\
\hline \hline
\end{tabular}

It can be seen that the PM eddy current loss is effectively decreased with the added copper shield, and the sleeve loss also decreases with the copper shield thickness. However, the shield loss and total rotor eddy current loss reduce initially, but then start to increase again as the copper shield gets thicker. The minimum total eddy current loss occurs when the copper shield thickness is $1.2 \mathrm{~mm}$, but the total rotor eddy current loss is still greater than that without a copper shield. However, copper has a relatively large thermal conductivity, which is beneficial for rotor heat dissipation. Moreover, the composite rotor structure can also impact the machine's antidemagnetization capability, as will be illustrated in section IV.

\section{Windage Loss}

The windage loss is due to the air friction when the rotor rotates and it becomes significant as the machine speed increases. The rotor can be approximately modeled as a cylinder with its windage loss analytically calculated according to [16]:

$$
P_{\text {windage }}=C_{f} \pi \rho \omega^{3} r^{4} l
$$

where $\rho$ denotes air gap density, $\omega$ is the angular speed, $r$ and $l$ are the rotor radius and length respectively. $C_{f}$ is the friction coefficient which is determined by the air gap structure and rotor surface condition. As the analytical calculation method is based on several empirical coefficients, alternatively, the air gap friction loss can be calculated more accurately through fluid field analysis. Fig.9 shows the ventilation model for the high speed PMSM. The groove in the model is the ventilation region in the stator slots as shown in Fig.1.

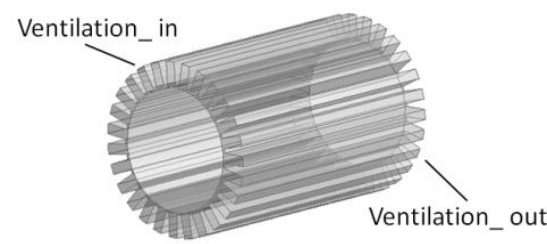

Fig. 9. Air gap and ventilation groove model 
Fig. 10 shows the relationship between windage losses for different rotor roughness heights as a function of rotor speed, while Fig. 11 provides a comparison of windage losses for different axial air ventilation speeds with the machine operating at rated speed. It can be observed that the windage losses grow approximately exponentially with rotor speed, and hence increase dramatically as the machine speed rises. The rotor surface roughness is also a critical factor with the windage loss also increasing with the roughness of the rotor surface. The axial ventilation path is beneficial for decreasing machine temperature, but adds an extra windage loss to the total losses. Thus, it is advantageous to use a sleeve material with a smooth surface and employ a suitable ventilation speed for high speed PMSMs.

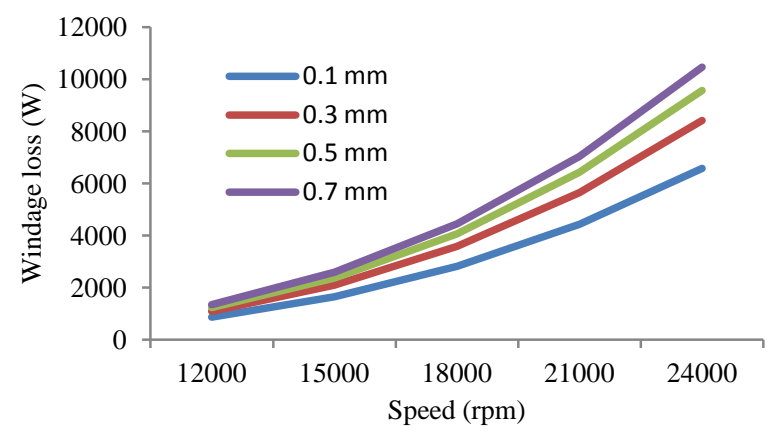

Fig. 10. Relationship between windage losses and rotor speed for different rotor roughness heights

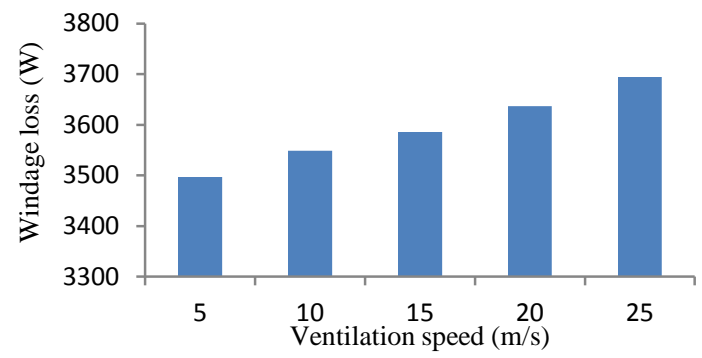

Fig. 11. Windage losses with ventilation speeds

\section{Demagnetization ANALYsis}

The demagnetization of PMs may occur due to high temperature and armature reaction. The demagnetization curve for NdFeB (NEOMAX-38H) is shown in Fig.12. This shows

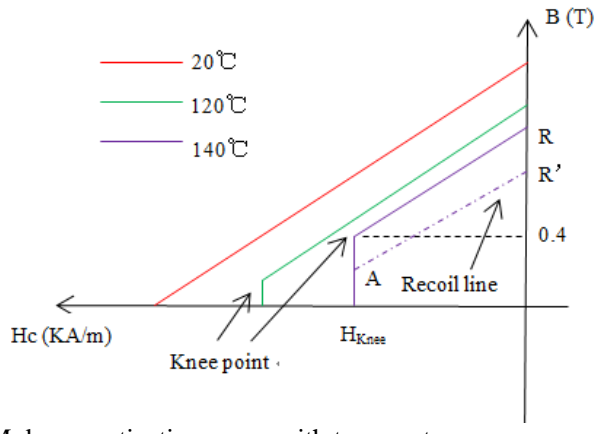

Fig. 12. PM demagnetization curve with temperature that if the flux density in PMs is below the knee point (point A), PM remanence will change from the origin point (R) to a new point ( $\left.\mathrm{R}^{\prime}\right)$ through the recoil line. In this paper, PM demagnetization is assessed using the demagnetization ratio, which is defined as the ratio of the residual flux density loss after demagnetization to the original PM residual flux density.

Demagnetization due to temperature is evaluated for an overloaded machine, namely, the high speed PMSM powered by twice the rated current in amplitude. Fig.13 shows the demagnetization ratio of the PMs for this setup at different temperatures. As can be seen, no demagnetization occurs when the operational temperature is $100{ }^{\circ} \mathrm{C}$; partial demagnetization takes place at the edge of PMs when the temperature increases to $120{ }^{\circ} \mathrm{C}$; and it becomes more severe at the PM corners as the temperature rises to $140{ }^{\circ} \mathrm{C}$ and $160^{\circ} \mathrm{C}$. This is due to the fact that the magnetic reaction flux concentrates at the corners. The winding current also has a critical effect on PM demagnetization. Fig.14 demonstrates the output torque under different current excitations $(1.5,2,3,4$ times of rated current in amplitude) as the temperature varies according the following profile: the temperature is initially constant at the operating temperature of $60{ }^{\circ} \mathrm{C}$, then it increase to $140{ }^{\circ} \mathrm{C}$ at $0.008 \mathrm{~s}$ before returning back to $60{ }^{\circ} \mathrm{C}$ at $0.02 \mathrm{~s}$. Clearly, the torque is able to return to its initial value when the PMSM is powered by a current that is 1.5 times the rated value; while the recovered torque is lower than its initial value with larger currents. Moreover, the recovered torque at 3times the rated current is close to that at 4-times the rated current, indicating that considerable demagnetization occurs when 3-times the rated current is applied to the PMSM at $140{ }^{\circ} \mathrm{C}$.
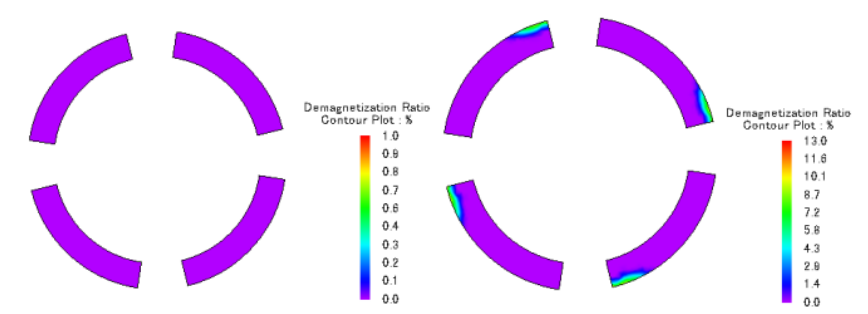
(a) $100{ }^{\circ} \mathrm{C}$

(b) $120^{\circ} \mathrm{C}$

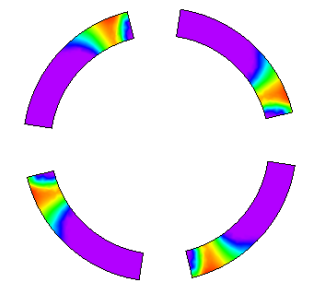

(c) $140{ }^{\circ} \mathrm{C}$

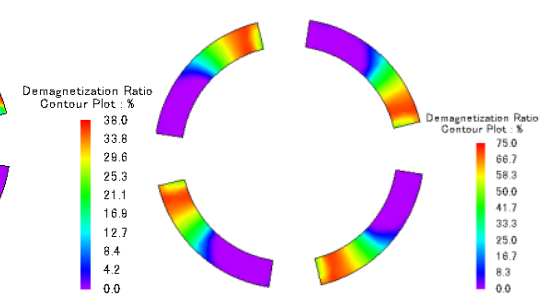

(d) $160^{\circ} \mathrm{C}$

Fig.15 compares the back electromotive force (EMF) waveform as a result of the demagnetization effect arising from over loading current in amplitude of the stator winding at $140{ }^{\circ} \mathrm{C}$. As can be seen not only does the EMF amplitude decrease, the EMF waveform is also distorted after demagnetization.

Fig. 16 provides a comparison of the PM demagnetization that occurs when the rotor does not have a copper shield and 
when it is a composite rotor structure with a copper shield.

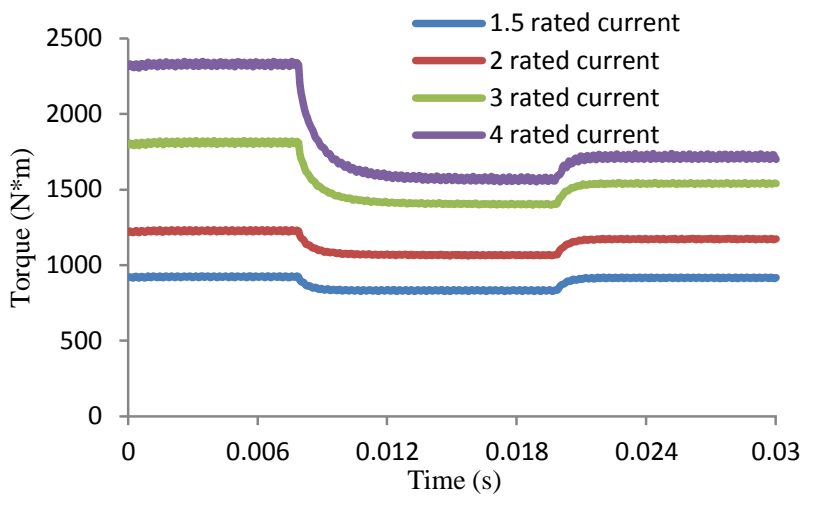

Fig. 14. Torque under winding current

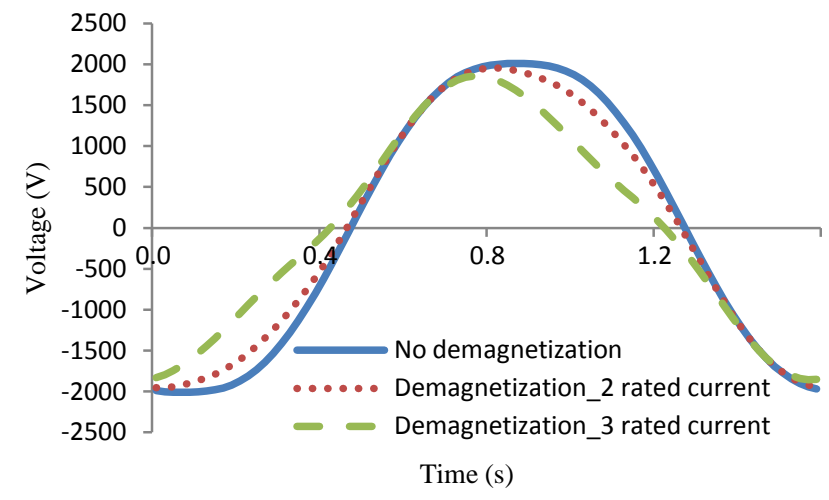

Fig. 15. Back EMF waveform after demagnetization

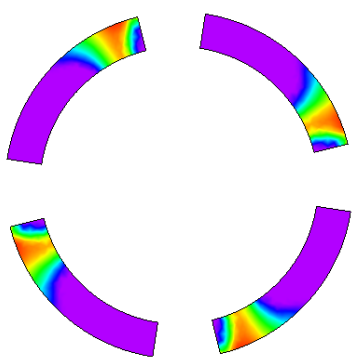

(a) no copper shield
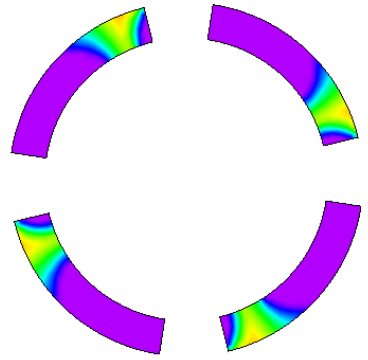

(b) $0.6 \mathrm{~mm}$ copper shield

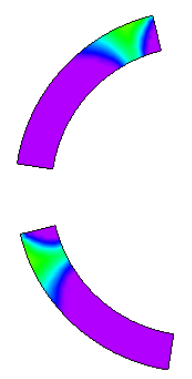

(c) $1.2 \mathrm{~mm}$ copper shield

Fig. 16. Demagnetization analysis

This analysis is for the machine operating at twice the rated winding current amplitude applied at $140{ }^{\circ} \mathrm{C}$. This shows that the composite rotor structure decreases the exterior magnetic field effect on PMs due to the magnetic shielding effect of the copper layer, reducing the level and area of demagnetization for the harsh operating conditions. Therefore, it can be concluded that the composite rotor structure with copper shield can effectively improve the anti-demagnetization capacity of machines.

\section{THERMAL ANALYSIS}

A CFD model for the high speed PMSM is constructed to investigate the cooling ventilation and temperature distribution using an electro thermal-fluid coupling analysis. The electromagnetic losses are regarded as heat sources for thermal analysis, while the forced air cooling is achieved via the air blown axially into the machine from one end to facilitate winding and rotor heat dissipation. Furthermore, the circumferential groove is also ducted around the machine frame for water cooling. Only 1/27 of the machine is modeled with periodic boundaries applied, while rotor rotation is considered by setting moving wall conditions at rated speed on the rotor surface. Standard K- $\varepsilon$ model is adopted for turbulent flow calculation with viscous dissipation term included in the energy equation to consider the air drag effect for the rotor under high speed operation. The iterative process is also adopted during the electro thermal-fluid coupling analysis to include the influence of the machine operating temperature on machine electromagnetic performance, as the machine material electromagnetic properties vary with operating temperature. Firstly, the losses of the different components in the machine at an initial temperature $\mathrm{T}_{\mathrm{k}}$ are obtained through electromagnetic analysis. These are then sent to CFD fluidthermal analysis as heat sources; and an updated temperature $\mathrm{T}_{\mathrm{k}+1}$ determined. The material electromagnetic properties of the machine components are then replaced by new values corresponding to the new working temperature $\mathrm{T}_{\mathrm{k}+1}$ for the next coming electromagnetic analysis; the electro thermalfluid analysis is processed iteratively until the maximum temperature difference between $T_{k+1}$ and $T_{k}$ is less than a preset tolerance.

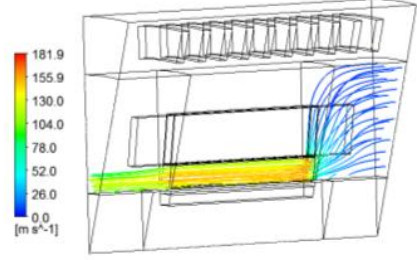

(a) Velocity streamline

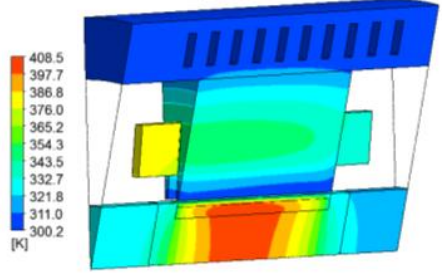

(b) Temperature field distribution

Fig. 17. CFD results for the high speed PMSM under rated condition

Fig.17 shows the CFD calculation results for the high speed PMSM under rated load condition. As can be seen, the highest temperature in the machine occurs in the middle of the rotor and gradually decreases towards both ends, while the hottest spot on the winding and stator are located near the cooling air outlet. Both water cooling and air cooling can effectively act to constrain the temperature rise in the machine components.

Fig. 18 further compares the PM temperature for different air flow rates: the increase in air speed can obviously decrease the PM temperature, as the temperature is $424.9 \mathrm{~K}\left(151.7{ }^{\circ} \mathrm{C}\right)$ 
in $\mathrm{PM}$ when the air flow rate is $5 \mathrm{~m} / \mathrm{s}$, while it drops to 408.5 $\mathrm{K}\left(135.3{ }^{\circ} \mathrm{C}\right)$ when the air flow rate increases to $10 \mathrm{~m} / \mathrm{s}$. Hence, a moderate increase in the ventilation air flow rate is an effective method of reducing the temperature of the PMs for the machine during high speed operation.

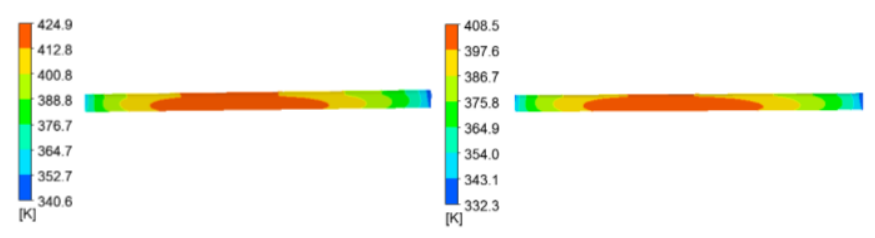

(a) $5 \mathrm{~m} / \mathrm{s}$

(b) $10 \mathrm{~m} / \mathrm{s}$

Fig. 18. Temperature distribution for PM under different air flow rates

\section{EXPERIMENTAL TESTS}

The proposed MW high speed PMSM has been prototyped and experimentally tested. The stator core with windings and the rotor of the high speed PMSM are shown in Fig. 19 (a) and (b), respectively.

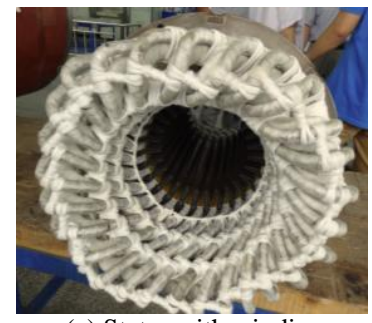

(a) Stator with windings

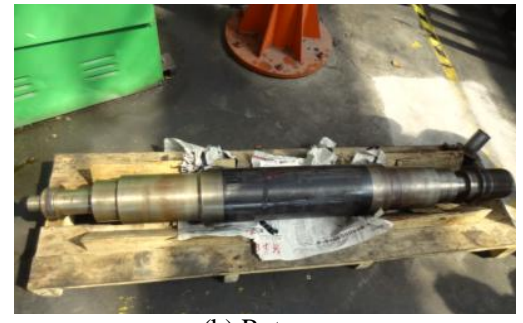

(b) Rotor
Fig. 19. Stator and rotor for high speed PMSM

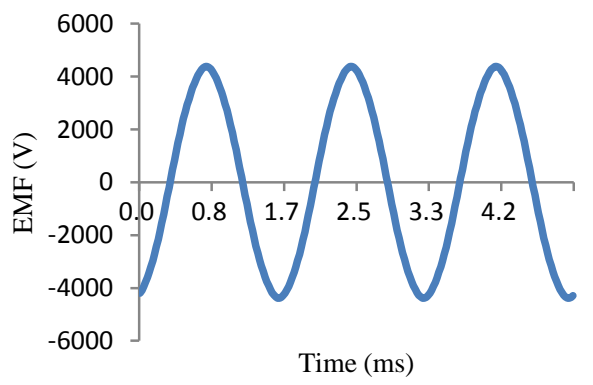

(a) EMF by FEM

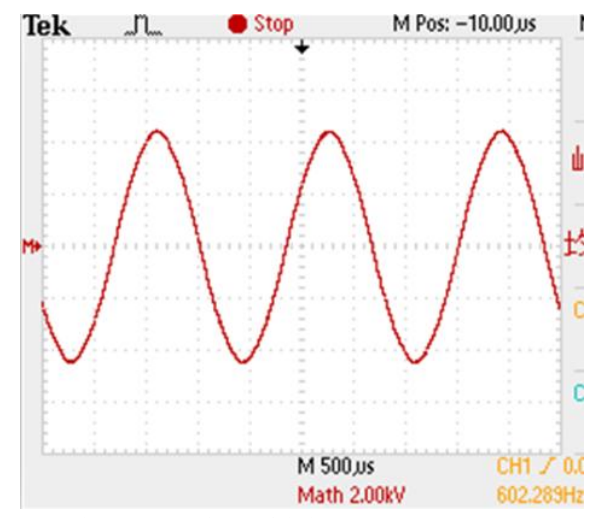

(b) EMF ( $2 \mathrm{kV} /$ grid) by measurement

Fig. 20. Line-line EMF
Fig. 20 shows the no-load line-line EMF waveforms of the high speed PMSM at rated speed from FEM and experimental tests. Clearly, the numerical and experimental results are in good agreement with respect to the EMF.

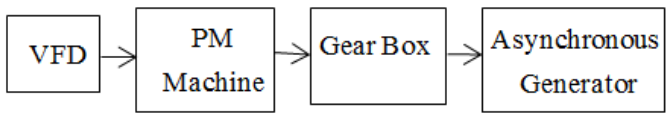

(a) Load test scheme

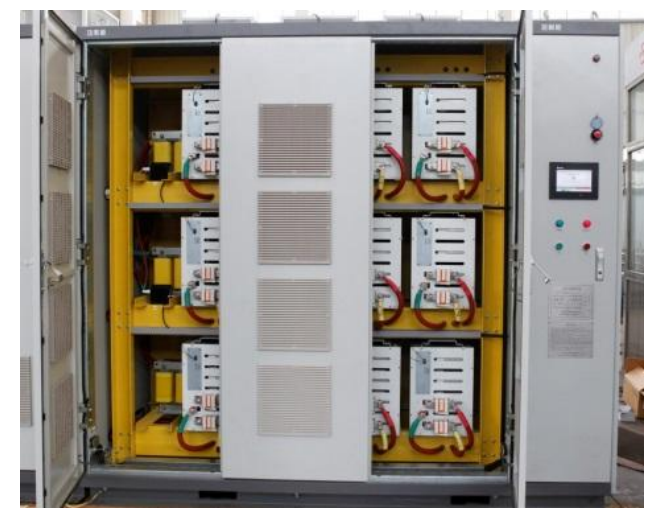

(b) Nine-level high voltage inverter

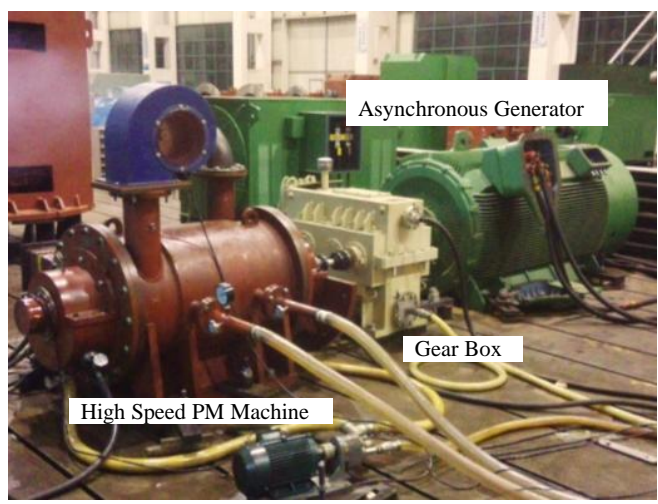

(c) Load test

Fig. 21. Load test for high speed PM machine

The load tests for the developed high speed PMSM are based on the scheme shown in Fig.21 (a). The machine is powered by variable frequency drive (VFD) with voltage. It drives an asynchronous generator with the coupling between the two machines achieved using a gear box. Hence, the high speed PMSM output can be reflected in the power generated by the asynchronous generator. The VFD is a nine level high voltage inverter with vector control method applied to achieve control in both machine speed and power during high speed operation. The nine level high voltage inverter (as shown in Fig.21 (b)) has the advantage of powering the machine with low harmonics, and it is a desirable solution for high power rate high speed machine drive. Fig 21 (c) shows the test rig for load testing the high speed PMSM. Fig. 22 presents the winding phase current of the machine at the rated speed (18000 rpm) and rated load condition. The measured power factor is 0.966 . The winding currents are shown as sinusoidal waveforms and the measurement results agree well with the numerical results from the FEM calculation. 


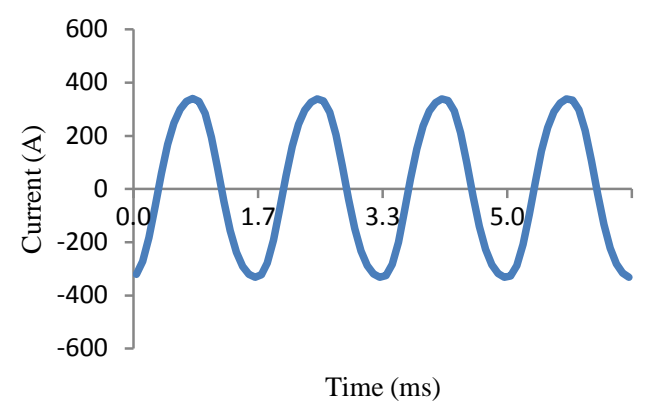

(a) Winding phase current by FEM

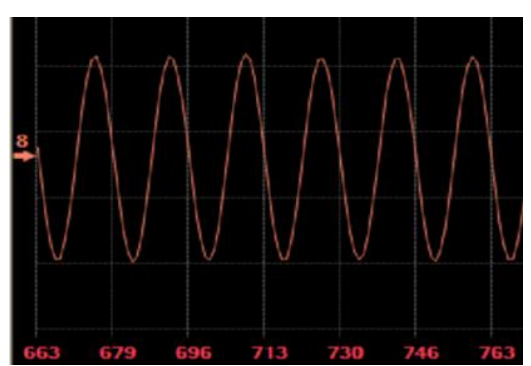

(b) Winding phase current by measurement (200A/grid)

Fig. 22. Phase current for the high speed PM machine at rated load

Table V and VI present the experimental test results of the whole high speed PMSM system performance at different loads. The input power to the VFD and the output power of asynchronous generator are measured when the PMSM operates at 10,200 rpm and 18,000 rpm, respectively. Considering that the results listed are for the whole test system including the gear box, it can be concluded from the measurements that the designed high speed PM machine achieves a desirable performance.

TABLE V EXPERIMENTAL MEASUREMENTS WITH THE PM MACHINE AT 10200 RPM UNDER DIFFERENT LOADS

\begin{tabular}{cccccc}
\hline \hline $\begin{array}{c}\text { Voltage } \\
(\mathrm{V})\end{array}$ & $\begin{array}{c}\text { VFD } \\
\text { Current }\end{array}$ & $\begin{array}{c}\text { Power } \\
(\mathrm{kW})\end{array}$ & $\begin{array}{c}\text { Voltage } \\
(\mathrm{V})\end{array}$ & $\begin{array}{c}\text { Current } \\
(\mathrm{A})\end{array}$ & $\begin{array}{c}\text { Power } \\
(\mathrm{kW})\end{array}$ \\
\hline 9867 & 9.0 & 149.6 & 1758 & 45.6 & 113.5 \\
9744 & 15.2 & 250.7 & 2395 & 61.8 & 213.1 \\
9800 & 21.1 & 349.3 & 2882 & 74.3 & 306.8 \\
9805 & 27.0 & 445.7 & 3000 & 89.4 & 399.4 \\
9720 & 36.6 & 595.8 & 3115 & 113.0 & 535.7 \\
\hline \hline
\end{tabular}

TABLE VI EXPERIMENTAL MEASUREMENTS WITH THE PM MACHINE AT 18000 RPM UNDER DIFFERENT LOADS

\begin{tabular}{cccccc}
\hline \hline \multirow{2}{*}{$\begin{array}{c}\text { Voltage } \\
(\mathrm{V})\end{array}$} & $\begin{array}{c}\text { Current } \\
(\mathrm{A})\end{array}$ & $\begin{array}{c}\text { Power } \\
(\mathrm{kW})\end{array}$ & $\begin{array}{c}\text { Voltage } \\
(\mathrm{V})\end{array}$ & $\begin{array}{c}\text { Current } \\
(\mathrm{A})\end{array}$ & $\begin{array}{c}\text { Power } \\
(\mathrm{kW})\end{array}$ \\
\hline 9535 & 33.5 & 535.4 & 3516 & 82.6 & 423.8 \\
9572 & 40.2 & 643.2 & 3488 & 101.2 & 516.0 \\
9482 & 50.8 & 803.5 & 3490 & 129.6 & 654.0 \\
9585 & 56.5 & 903.1 & 3499 & 147.7 & 735.9 \\
9527 & 63.0 & 999.6 & 4018 & 140.4 & 835.0 \\
9534 & 63.2 & 1003.8 & 4016 & 140.8 & 836.7 \\
9924 & 69.3 & 1146.0 & 3981 & 157.7 & 921.5 \\
\hline \hline
\end{tabular}

In order to verify the temperature field prediction, the temperature resister detectors are installed in the winding and stator yoke at the air flow inlet and outlet sides, respectively. The prototype machine is tested under the rated conditions (current and speed). Fig.23 shows the temperature measurement device. During the test, the machine is operated at rated conditions and reaches a steady state. Then the related temperatures are recorded for further comparison. As shown in Table VII, the temperature of the winding and stator near the air flow outlet is higher than that near the inlet, and the predicted values from CFD analysis are very close to the measured temperatures. Overall the experimental tests have validated the developed numerical models in predicting key power losses in the machine.

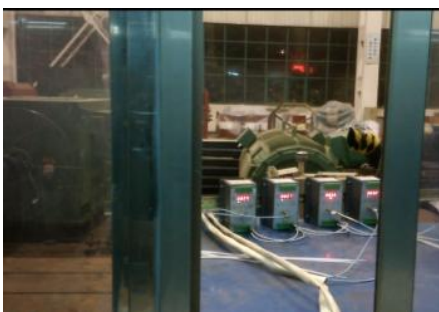

Fig. 23. Temperature measurement device

TABLE VII

TEMPERATURE FOR HIGH SPEED PM MACHINE $\left({ }^{\circ} \mathrm{C}\right)$

\begin{tabular}{ccccc}
\hline \hline & \multicolumn{2}{c}{ Inlet } & \multicolumn{2}{c}{ Outlet } \\
& Winding & Stator yoke & Winding & Stator yoke \\
\hline CFX & 65.3 & 52.1 & 110.3 & 62.5 \\
Measurement & 68.8 & 55.8 & 114.5 & 66.2 \\
\hline \hline
\end{tabular}

\section{CONCLUSION}

In this paper, a MW level high speed PMSM is analyzed with detailed electromagnetic and thermal performance. Iron loss is calculated based on an improved method. It can be found that harmonics and rotational magnetic field effects should be considered in high speed PMSM iron loss estimation for higher precision. Rotor eddy current loss performance is discussed with the machine structure and rotor sleeve impacts illustrated. The Eddy current loss can be decreased by employing the multi-slot stator structure, while application of a low conductivity and thin sleeve (taking account of mechanical constraints) can reduce the rotor eddy current loss. The mechanical friction loss is also estimated with reasonable accuracy. The PM's demagnetization causes degradation in machine performance, and a composite rotor structure is proposed to effectively improve the machine's anti-demagnetization capacity under harsh operation conditions. The temperature distribution of the high speed PMSM under rated condition is calculated based on a CFD fluid-thermal coupling analysis, and the reduction in the rotor temperature rise can be achieved by axial air cooling ventilation. The research and effectiveness of the FEM and CFD models for the proposed high speed PMSM have been verified by experimental measurements on a prototype machine. 


\section{REFERENCES}

[1] D. Gerada, A. Mebarki, N. Brown, C. Gerada, A. Cavagnino and A. Boglietti, "High-speed electrical machines: technologies, trends, and developments," IEEE Trans. Industrial Electronics, vol. 61, no. 6, pp. 2946-2959, Jun. 2014.

[2] Z. Konlondzovski, A. Arkkio, J. Larjola and P. Sallinen, "Power limits of high speed permanent magnet electrical machines for compressor applications," IEEE Trans. Energy Conversion, vol. 26, no. 1, pp. 7382, Mar. 2011

[3] N. Uzhegov, E. Kurvinen, J.Nerg, J. Pyrhonen, J. Sopanen and S. Shirinskii"Multidisciplinary design process of a 6-slot 2-pole high speed permanent-magnet synchronous machine," IEEE Trans. Industrial Electronics, vol. 63, no. 2, pp. 784-795, Feb. 2016.

[4] J. Kim, I. Jeong, K. Nam, J. Yang and T. Hwang, "Sensorless control of PMSM in a high speed region considering iron loss," IEEE Trans. Industrial Electronics, vol. 62, no. 10, pp. 6151-6159, Oct. 2015.

[5] S. Jang, H. Cho, S. Lee H. Yang and Y. Jeong, "The influence of magnetization pattern on the rotor losses of permanent magnet high speed machines," IEEE Trans. Magnetics, vol. 62, no. 10, pp. 61516159 , Oct. 2015

[6] Z. Kolondzovski, A. Belahcen and A. Arkkio, "Comparative thermal analysis of different rotor types for a high speed permanent magnet electrical machine," IET Electric Power Applications vol. 3, no. 4, pp. 279-288, Apr. 2008

[7] Z. Huang, J. Fang, X. Liu and B. Han, "Loss calculation and thermal analysis of rotor supported by active magnetic bearings for high speed permanent magnet electrical machines," IEEE Trans. Industrial Electronics, vol. 63, no. 4, pp. 2027-2035, Apr. 2016.

[8] Y. Huang, J. Dong, J. Zhu and Y. Guo, "Core loss modeling for permanent magnet motor based on flux variation locus and finite element method," IEEE Trans. Magnetics, vol. 48, no. 2, pp. 10231026, Feb. 2012

[9] S. Zhu, M. Cheng, J. Dong and J. Du, "Core loss analysis and calculation of stator permanent magnet machine considering DC-biased magnetic induction," IEEE Trans. Industrial Electronics, vol. 61, no. 10, pp. 5203-5212, Oct. 2014.

[10] J. Seo, D. Woo, T. Chung and H. Jung, "A study on loss characteristics of IPMSM for FCEV considering," IEEE Trans. Magnetics, vol. 46 no. 8, pp. 3213-3216, Aug. 2010.

[11] J. Seo, T. Chung, C. Lee, S. Jung and H. Jung, "Harmonic iron loss analysis of electrical machines for high speed operation considering driving condition," IEEE Trans. Magnetics, vol. 45, no. 10, pp. 46564659 , Oct. 2009

[12] Z. Zhu, K. Ng, N. Schofield and D. Howe, "Improved analytical modeling of rotor eddy current loss in brushless machines equipped with surface-mounted permanent magnets," IEE Proceedings, vol. 151, no. 6, pp. 641-650, Nov. 2004.

[13] D. Ishaak, Z. Zhu and D. Howe, "Eddy-current loss in the rotor magnets of permanent magnet brushless machines have a fractional number of slots per pole," IEEE Trans. Magnetics, vol. 41, no.9, pp. 2462-2469, Sep. 2005.

[14] W. Li, H. Qiu, X. Zhang and R. Yi, "Influence of copper plating on electromagnetic and temperature fields in a high speed permanent magnet generator," IEEE Trans. Magnetics, vol. 48, no.8, pp. 22472253, Aug. 2012.

[15] J. Shen, H. Hao, M. Jin and C. Yuan, "Reduction of Rotor Eddy Current Loss in High Speed PM Brushless Machine by Grooving Retaining Sleeve," IEEE Trans. Magnetics, vol. 49, no.7, pp. 3973-3976, Jul. 2013.

[16] J. Xing, F. Wang, T. Wang and Y. Zhang, "Study on antidemagnetization of magnet for high speed permanent magnet machine," IEEE Trans. Applied superconductivity, vol. 20, no. 3, pp. 856-860, Jun. 2010.

[17] J. Dong, Y. Huang, L. Jin, B. Guo, H. Lin, J. Dong, M. Cheng and H. Yang, "Electromagnetic and thermal analysis of open-circuit air cooled high-speed permanent magnet machines with gramme ring windings," IEEE Trans. Magnetics, vol. 50, no. 11, pp. 1-4, Nov. 2014.

[18] J. Dong, Y. Huang, L. Jin, H. Lin and H. Yang, "Thermal optimization of a high speed permanent magnet motor," IEEE Trans. Magnetics, vol. 50, no. 2, pp. 1-4, Feb. 2014.

[19] Z. Zhang, L. Yu, L. Sun, L. Qian and X. Huang, "Iron loss analysis of doubly salient brushless DC generators," IEEE Trans. Industrial Electronics, vol. 62, no. 4, pp. 2156-2163, Apr. 2015.
[20] L. Ma, M. Sanada, S. Morimoto and Y. Takeda, "Prediction of iron loss in rotating machines with rotational loss included," IEEE Trans. Magnetics, vol. 39, no. 4, pp. 2036-2041, Jul. 2003.

[21] L. Papini, T.Raminosoa, D. Gerada and C. Gerada, "A high speed permanent magnet machine for fault tolerant drivetrains," IEEE Trans. Industrial electronics, vol. 61, no. 6, pp. 3071-3080, Jun. 2014.

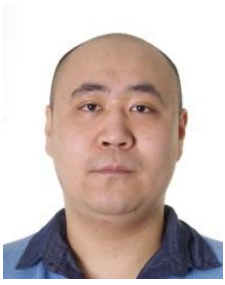

Yue Zhang (S'15) was born in Shenyang, China. He received the B.Eng. degree from Shenyang University of Technology, Shenyang, China, in 2011 and the M.Eng. degree from Zhejiang University, Hangzhou, China in 2014, both in Electrical Engineering. He has been working toward the Ph.D. degree in the Department of Electronics, Electrical Engineering and Computer Science, Queen's University Belfast, Belfast, U.K., since 2014

His research interests include the design and analysis of electrical machines for industrial applications and electrical vehicles.

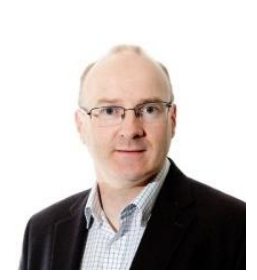

Seán McLoone (S'94-M'96-SM'02) received an M.E. degree in Electrical and Electronic Engineering and a $\mathrm{PhD}$ in Control Engineering from Queen's University Belfast, Belfast, U.K. in 1992 and 1996, respectively.

$\mathrm{He}$ is currently a Professor and Director of the Energy Power and Intelligent Control Research Cluster at Queen's University Belfast. His research interests are in Applied Computational Intelligence and Machine Learning with a particular focus on data based modelling and analysis of dynamical systems, with applications in advanced manufacturing informatics, energy and sustainability.

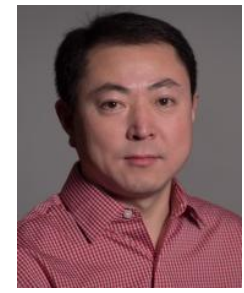

Wenping Cao (M'05-SM'11) received the B.Eng. in Electrical Engineering from Beijing Jiaotong University, Beijing, China in 1991 and Ph.D. degree in electrical machines and drives from the University of Nottingham, Nottingham, U.K., in 2004. He is currently a Chair Professor of Electrical Power Engineering and the Head of Power Electronics, Machines and Power System (PEMPS) Group at Aston University, Birmingham, U.K.

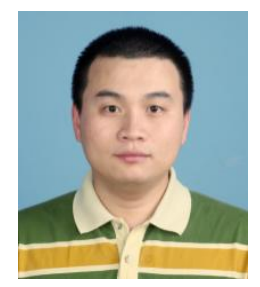

Fengyi Qiu was born in Qidong, Jiangsu, China. He received the B.Eng. degree from Hohai University, Nanjing, China, in 2009. He is now with Jiangsu Aerospace Power Electric Co., Ltd, Jingjiang, China.

His research interests include electrical machine design and manufacture technology.

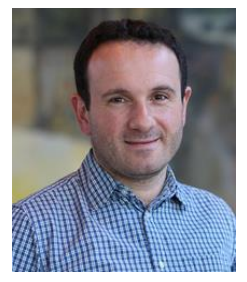

Chris Gerada (M'05) received the Ph.D. degree in numerical modeling of electrical machines from The University of Nottingham, Nottingham, U.K., in 2005. He subsequently worked as a Researcher with The University of Nottingham on high-performance electrical drives and on the design and modeling of electromagnetic actuators for aerospace applications. Since 2006, he has been the Project Manager of the GE Aviation Strategic Partnership. In 2008, he was appointed as a Lecture in electrical machines; in 2011, as an Associate Professor; and in 2013, as a Professor at The University of Nottingham. His main research interests include the design and modeling of high-performance electric drives and machines. Prof. Gerada serves as an Associate Editor for the IEEE TRANSACTIONS ON INDUSTRY APPLICATIONS and is the past Chair of the IEEE IES Electrical Machines Committee. 